\title{
RESEARCH
}

Open Access

\section{The NIHSS score can predict the outcome of patients with primary intracerebral hemorrhage}

\author{
Mohammed Elsayed Mahdy ${ }^{*}$ (D, Nesma Abdelmonem Ghonimi, Tamer Sabry Elserafy and Wael Mahmoud
}

\begin{abstract}
Introduction: Intracerebral hemorrhage $(\mathrm{ICH})$ is characterized to be the most lethal form of stroke, with high rates of mortality, not only during the acute phase (39\%), but also 3 months later (33.5\%) with a significant long-term disability. The National Institutes of Health Stroke Scale (NIHSS) score is a purely clinical scale, is easily administrable, and does not require the use of any additional diagnostic procedure.
\end{abstract}

Objectives: To evaluate if the admission NIHSS score in acute primary ICH patients can be a predictive tool for their short-term outcome.

Patient and methods: We included 120 patients diagnosed with spontaneous ICH. All patients were subjected to full history taking, general, and neurological examination with assessment of neurological function on admission using the NIHSS. Laboratory assessment on admission including complete blood count, routine liver and kidney functions, and coagulation profile. Radiological investigations included computerized tomography (CT). The patients were followed, both clinically using the NIHSS score, radiologically with CT brain after 1 week and 4 weeks from the onset to assess the hematoma growth, its complications, and or resolution. Modified Rankin score (mRS) was done after 30 days of onset to assess patient's disability.

Results: The 30-day mortality was about one third of the patients. The intracerebral hematoma volume on admission has a significant positive correlation with the NIHSS, and ICH score significantly correlates with the 30day outcome.

Conclusion: Admission NIHSS has an independent predictive value of the 30-day outcome in cases of primary ICH as regards mortality and disability.

Keywords: Primary intracerebral hemorrhage, Outcome, NIHSS score

\section{Introduction}

Primary intracerebral hemorrhage (ICH) is the most ominous cerebrovascular catastrophe and accounts for about $10 \%$ of all strokes in Western populations and $15 \%$ worldwide [1]. Recently, according to the global burden of disease study in 2010, the incidence of ICH in Egypt was estimated to be 49.9-61.2 patients per 100,000 persons, at the year 2010 , so the incidence is increased in comparison to what was estimated at 1990 (40.8-47.4 per 100,000 persons) [2]. No apparent cause is found in about $80 \%$ of cases, hence called primary

\footnotetext{
* Correspondence: mdymahdy@yahoo.com

Zagazig Faculty of Medicine, Zagazig University Hospitals (ZUH), Zagazig, Egypt
}

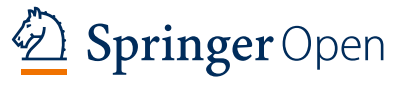

(c) The Author(s). 2019 Open Access This article is distributed under the terms of the Creative Commons Attribution 4.0 International License (http://creativecommons.org/licenses/by/4.0/), which permits unrestricted use, distribution, and reproduction in any medium, provided you give appropriate credit to the original author(s) and the source, provide a link to the Creative Commons license, and indicate if changes were made.

$\mathrm{ICH}$, and it is commonly attributed to small vessel vasculopathies specially those that supply the basal ganglia, thalamus, and brain stem [3, 4]. It has a high risk of poor long-term outcome with risk of mortality about $40 \%$. Its treatment is largely supportive, aiming at promoting recovery, with no Food and Drug Administration (FDA) approved medical or surgical treatment $[5,6]$. The NIHSS was originally designed as a research tool to measure baseline data on patients in acute stroke clinical trials. Now, the scale is also widely used as a clinical assessment tool to evaluate acuity of stroke patients, determine appropriate treatment, and predict patient outcome, and it may be considered as a better predictive factor for outcome in primary ICH than using Glasgow 
Coma Scale (GCS) alone. It is suggested to be an independent predictor of outcome in different cohorts of $\mathrm{ICH}$ patients on multivariate analyses $[7,8]$. In this context, our study was designed to evaluate the outcome predictive value of admission NIHSS in patients with acute primary $\mathrm{ICH}$.

\section{Subjects and methods}

The study was approved by the local neurology department ethical committee.

\section{Technical design}

According to the power of study, $80 \%$ and $95 \%$ confidence interval (CI), and the markers of severity and outcomes, the study included 120 patients over 1-year duration, 69 of them were males and 51 were females with the mean age of $62.54 \pm 11.45$ years. All patients older than 18 years with acute primary $\mathrm{ICH}$, who were admitted to Neuro-Critical Care Unit and Stroke Unit of Neurology Department of ZUH.

We excluded patients with age 18 years or less, head trauma, recent surgical intracranial hematoma evacuation, recent ischemic stroke, hemorrhagic transformation within acute cerebral ischemia, recent subarachnoid hemorrhage, chronic liver or kidney disease, and malignancy and patients presented after $72 \mathrm{~h}$ of onset after $\mathrm{ICH}$.

\section{Operational design}

An informed written consent was obtained from patient himself and or patient's first degree relatives when consciousness is impaired. A full history taking, stressing on vascular risk factors including hypertension, diabetes mellitus, dyslipidemia, smoking, use of anticoagulants, and previous stroke. Thorough general and neurological examination with assessment of neurological function on admission using Glasgow Coma Scale (GCS) and Intra-Cerebral Hemorrhage ( $\mathrm{ICH})$ score was done. The NIHSS score is an 11-item neurologic examination stroke scale used to evaluate the effect of acute cerebrovascular stroke on the levels of consciousness, language, neglect, visual-field loss, extraocular movement, motor strength, ataxia, dysarthria, and sensory loss. The maximum possible score is 42 , with the minimum score being 0 , each of score items given between 0 and $4[1,9]$. Also, laboratory assessment on admission including complete blood count with special interest on the total leukocyte count, urine analysis, and HB level. The computerized tomography, using GE ProSpeed Dual Slice F II CT with MX135 Tube, Cleveland, USA, was done for all patients on admission within the first $72 \mathrm{~h}$, after 1 week, and after 4 weeks from the onset with stress on identification of hematoma location and volume measured on initial brain CT scans using the formula $A \times$
$B \times C \times 0.5$, where $A$ and $B$ indicate the largest perpendicular diameters through the hyperdense area on the CT scan, and $C$ indicates the thickness of the hematoma which equal to the number of slices containing hemorrhage [10]. It was then classified according to the ICH score into $<30 \mathrm{~cm}^{3}$ and $\geq 30 \mathrm{~cm}^{3}$. In addition, the following parameters were assessed: midline shift was classified into three categories according to Lobato classification as $<5-\mathrm{mm}, 5-15-\mathrm{mm}$, and $>15-\mathrm{mm}$ [7] hematoma growth (which indicates the expansion or increase in its volume about $33 \%$ or $12.5 \mathrm{ml}$ in subsequent follow-up CTs [8]; the presence of perifocal edema as mild, moderate, and severe; and intraventricular hematoma extension whether involving lateral and/or third and/or fourth ventricles). All included patients were reassessed after 1 week and 4 weeks from the onset both clinically using the NIHSS score where neurological deterioration was defined as an increase of the score $\geq 4$ points than the baseline score [8] and radiologically with plain CT brain to assess the hematoma growth, its complications or resolution, and the correlation between patient's NIHSS and hematoma parameters in follow-up CT of the brain. Patients' outcome was assessed using modified Rankin scale (mRs) on discharge from hospital at 30 days.

\section{Statistical analysis}

All data were analyzed using SPSS 18.0 for Windows (SPSS Inc., Chicago, IL, USA) and MedCalc 13 for Windows (MedCalc Software bvba, Ostend, Belgium). To determine predictors for overall mortality, any variables with $p$ value $\leq 0.05$ in univariate analysis were subjected to multivariate logistic regression analysis with forward method for entering of covariates. All tests were two sided. $p<0.05$ was considered statistically significant (S), $p<0.01$ was considered highly statistically significant (HS), and $p \geq 0.05$ was considered nonstatistically significant (NS).

\section{Results}

The included patients in our study were 120 patients, 69 of them were males and 51 were females. The overall mortality was 33 patients (27.5\%), 16 patients died in the first week after onset (13.3\%) and 17 patients died after the first week (14.16\%). Regarding the NIHSS, the prevalent scores were moderate (5-15) in 51 patients (43.3\%), severe (21-42) in 36 patients (30\%), and moderately severe $(16-20)$ in 28 patients $(23.3 \%)$ as shown in (Table 1). Admission leukocytosis, hyperglycemia, ESR, CRP, hematoma volume, and midline shift were all positively correlated with the used scores (NIHSS, ICH, and mRS) and inversely correlated with GCS (Table 2). There was a high significant correlation between overall mortality and hematoma volume, midline shift, intraventricular extension, ICH score, and NIHSS (Table 2). Blood pressure measurements were 
Table 1 NIHSS score categories among patients

\begin{tabular}{lll}
\hline Score & The studied patients $(N=120)$ \\
\hline NIHSS & $18.07 \pm 7.66$ & \\
Mean \pm SD & $16(3-38)$ & $0 \%$ \\
Median (range) & 0 & $3.3 \%$ \\
Score 0 & 4 & $43.3 \%$ \\
Score 1-4 & 52 & $23.3 \%$ \\
Score 5-15 & 28 & $30 \%$ \\
Score 16-20 & 36 & \\
Score 21-42 &
\end{tabular}

NIHSS National Institute of Health Stroke Scale

positively correlated with the NIHSS and negatively correlated with ICH score (Table 3). In multivariate analysis (forward method), admission NIHSS (OR 3.354(1.231-9.140), $p=0.018$ ), and initial hematoma volume in CT (OR $1.113(1.002-1.237), p=0.046)$; all can be independent predictors for 30-day mortality (Table 4).

\section{Discussion}

Primary $\mathrm{ICH}$ has been reported to be the most lethal form of stroke and to account for approximately $15 \%$ of all strokes worldwide. The rate of mortality and disability after $\mathrm{ICH}$, highlighting the pressing, needs to improve current therapy $[11,12]$.

The median case fatality at 30 days after primary $\mathrm{ICH}$ was found to be $40.4 \%$; ranging from 13 to $61 \%$, with most deaths occurring within the first $48 \mathrm{~h}$ [13]. In our study, the overall 30-day mortality was 33 out of 120 patients (28.4\%) of which $13.8 \%$ was during the first week of onset and $14.6 \%$ during the subsequent 3 weeks. The remaining $71.6 \%$ had variable degrees of motor (67.2\%), speech (13.8\%), cognitive (8.6\%), visual field (6.9\%), and sensory $(6.9 \%)$ disabilities. The range of the recorded mRS was 1-6 points with no patients scored $0 / 6$ or $5 / 6$. Patients scored $1-2$ were $18.9 \%$, those with score $3-4$ were $52.6 \%$, and those patients who died had a score of 6/6. The outcome of our patients as regards the mortality and disability was almost like that of EL-Tallawy and colleagues [14], who reported that 32.3\% of their patients died within the first month. Similarly, Zis and colleagues [13], found that 30-day case fatality rate in their $\mathrm{ICH}$ patients was $31.9 \%$, as 61 patients died within 30 days after the ICH out of 191 patients included in their study. Also, Stein and colleagues [15] observed that 30 -day mortality was $28.6 \%$, but in contrast to our results regarding disability, they found only $17.4 \%$ of their patients showed a favorable functional outcome $(\mathrm{mRS} \leq 3)$ vs $56.8 \%$ in our patients. In 2013 , Hu and colleagues [16] reported that overall hospital mortality was $24.4 \%$ and mean time from admission to death was 10.5 \pm 18.5 days, of them, 36 patients died in the first $72 \mathrm{~h}$ due to neurological complications. Of their total sample, $21.8 \%$ recovered fully with no lasting squealed, while $50.4 \%$ improved after therapy but with lasting squealed, that discrepancy between their results and ours may be due to their larger sample size (266 vs 120 ), and also, not all their patients were of primary type of $\mathrm{ICH}$. In our results, the absence of patients that had an independent life activity after 1 month of ICH may be due to the relatively short time of follow-up, small sample size as compared to multicenter studies, and also due to the lower quality of complementary as nutritional, rehabilitation, and psychological treatment strategies.

The NIHSS score had originally validated for evaluation of ischemic stroke severity, and then, it has been tried to predict outcome of $\mathrm{ICH}$ [12]. In our study, the NIHSS range was $3-38$ with median of 16 points. There were $43.1 \%$ of patients who have NIHSS $5-15,31 \%$ with NIHSS $21-42$, and $24.1 \%$ with $16-20$ points. The hematoma volume was highly correlated to admission NIHSS $(p<0.001)$. This is in disagreement with the results of Christensen and colleagues [17], who found that hematoma volume on admission is not correlated to NIHSS $(p=0.494)$. This can be due to their much larger sample size 821 patients with primary ICH from 122 centers in 22 countries.

It is reported that $\mathrm{ICH}$ mortality is better predicted by the NIHSS than the GCS. An increased NIHSS score on admission impacts ICH outcomes unfavorably [18]. In our study, we found a highly statistically significant

Table 2 Predictors for overall mortality in the studied cross section $(N=120)$ by univariate analysis

\begin{tabular}{|c|c|c|c|c|c|}
\hline & $\beta$ & SE & OR $(95$ & & $p$ value \\
\hline Midline shift & +0.443 & 0.103 & 1.557 & $(1.273-1.903)$ & $<0.001(\mathrm{HS})$ \\
\hline Mod. edema & +1.540 & 0.734 & 4.666 & $(1.108-19.649)$ & $0.036(S)$ \\
\hline $\mathrm{IVH}$ & +0.197 & 0.505 & 7.172 & $(2.668-19.280)$ & $<0.001(\mathrm{HS})$ \\
\hline Follow up H. volume & +0.079 & 0.019 & 1.083 & $(1.042-1.125)$ & $<0.001(\mathrm{HS})$ \\
\hline $\mathrm{ICH}$ score & +2.118 & 0.421 & 8.317 & (3.647-18.970) & $<0.001(\mathrm{HS})$ \\
\hline NIHSS & +0.366 & 0.070 & 1.442 & $(1.258-1.653)$ & $<0.001(\mathrm{HS})$ \\
\hline
\end{tabular}

Proportional by chance accuracy criteria $=80.7 \%$. The model predicts overall accuracy rate $=84 \%$. Null model -2 log likelihood $=107.855$; full model -2 log likelihood $=66.203$. Overall model chi-square $=41.652$, d.f $=13, p<0.001$ (HS) Hosmer and Lemeshow goodness of fit test $p=0.624$ (NS), $\beta$ regression coefficient, SE standard error, OR odds ratio, $95 \% \mathrm{Cl} 95 \%$ confidence interval. $p<0.05$ is significant. $p<0.01$ is highly significant 
Table 3 Correlation between Glasgow Coma Score, Intracerebral Hemorrhage Score, National Institute of Health Stroke Score, Modified Rankin Score, and selected study parameters

\begin{tabular}{|c|c|c|c|c|c|c|c|c|}
\hline \multirow[t]{2}{*}{ Variables } & \multicolumn{2}{|l|}{ GCS } & \multicolumn{2}{|c|}{$\mathrm{ICH}$ score } & \multicolumn{2}{|l|}{ NIHSS } & \multicolumn{2}{|l|}{$\mathrm{mRS}$} \\
\hline & $r$ & $p$ value (Sig.) & $r$ & $p$ value (Sig.) & $r$ & $p$ value (Sig.) & $r$ & $p$ value (Sig.) \\
\hline Age (years) & -0.057 & 0.540 (NS) & +0.145 & 0.121 (NS) & +0.094 & 0.316 (NS) & +0.108 & 0.247 (NS) \\
\hline SBP $(\mathrm{mmHg})$ & -0.321 & $<0.001(\mathrm{HS})$ & +0.245 & $0.008(\mathrm{HS})$ & +0.359 & $<0.001(\mathrm{HS})$ & +0.161 & 0.084 (NS) \\
\hline WBCs $\left(\times 103 / \mathrm{mm}^{3}\right)$ & -0.259 & $0.005(\mathrm{HS})$ & +0.309 & $0.001(H S)$ & +0.282 & $0.002(\mathrm{HS})$ & +0.333 & $<0.001(\mathrm{HS})$ \\
\hline Random blood glucose (mg/dl) & -0.389 & $<0.001(\mathrm{HS})$ & +0.391 & $<0.001(H S)$ & +0.364 & $<0.001(\mathrm{HS})$ & +0.382 & $<0.001(\mathrm{HS})$ \\
\hline ESR & -0.397 & $<0.001(\mathrm{HS})$ & +0.368 & $<0.001(\mathrm{HS})$ & +0.422 & $<0.001(\mathrm{HS})$ & +0.355 & $<0.001(\mathrm{HS})$ \\
\hline CRP & -0.376 & $<0.001(\mathrm{HS})$ & +0.414 & $<0.001(\mathrm{HS})$ & +0.337 & $<0.001(\mathrm{HS})$ & +0.352 & $<0.001(\mathrm{HS})$ \\
\hline Volume of hematoma $\left(\mathrm{cm}^{3}\right)$ & -0.455 & $<0.001(\mathrm{HS})$ & +0.599 & $<0.001(\mathrm{HS})$ & +0.456 & $<0.001(\mathrm{HS})$ & +0.483 & $<0.001(\mathrm{HS})$ \\
\hline Midline shift (cm) & -0.463 & $<0.001(\mathrm{HS})$ & +0.468 & $<0.001(\mathrm{HS})$ & +0.386 & $<0.001(\mathrm{HS})$ & +0.481 & $<0.001(\mathrm{HS})$ \\
\hline
\end{tabular}

$S B P$ systolic blood pressure, WBCs white blood cells, ESR erythrocyte sedimentation rate, CRP C-reactive protein

relation $(p=0.001)$ between the 30 -day mortality and NIHSS. A matched result was reached by Cheung and Zou [7], and a retrospective study of cases was admitted to the regional in Hong Kong and found that in 142 patients with $\mathrm{ICH}$, was a statistically significant relation of the 30-day mortality to NIHSS $(p=0.000)$. Our results were also similar to the results of Finocchi and colleagues [19], who concluded that the NIHSS is a reliable tool of clinical monitoring and correlates with 30-day and 3-month mortality and functional outcome in subjects with ICH with a sensitivity of 93.5 and $92.2 \%$, specificity of 82.3 and $69.6 \%$, and GA of 87.8 and $80.8 \%$, respectively, at 1 and 3 months. In Essa and colleagues [20], a study included patients admitted to Alexandria Main University Hospital, with acute cerebrovascular stroke, during 6 months interval for November 2008 till April 2009; there were similar results regarding the significant relation between mortality following $\mathrm{ICH}$ and admission NIHSS $(p=0.001)$. This in agreement with the findings of Christensen and colleagues [17], in Factor Seven for Acute Hemorrhagic Stroke (FAST) trial which included 821 patients with sICH from 122 sites in 22 countries, that neurological deterioration and mortality were significantly related to NIHSS $(p<0.001)$. Similar results to ours were obtained by Bakhshayesh and

Table 4 Predictors for overall mortality in the studied cross section ( $N=120$ ) by multivariate analysis (forward method)

\begin{tabular}{llllll}
\hline & $\beta$ & SE & \multicolumn{2}{l}{ OR $(95 \% \mathrm{Cl})$} & $p$ value \\
\hline SBP $(\mathrm{mmHg})$ & -0.085 & 0.046 & 0.919 & $(0.839-1.006)$ & $0.069(\mathrm{NS})$ \\
Initial volume & +0.107 & 0.054 & 1.113 & $(1.002-1.237)$ & $0.046(\mathrm{~S})$ \\
NIHSS & +1.210 & 0.512 & 3.354 & $(1.231-9.140)$ & $0.018(\mathrm{~S})$ \\
Constant & -18.427 & & & & \\
\hline
\end{tabular}

Proportional by chance accuracy criteria $=89.7 \%$. The model predicts overall accuracy rate $=99 \%$. Null model -2 log likelihood $=91.177$; full model -2 log likelihood $=12.247$. Overall model chi-square $=78.930, \mathrm{~d} . \mathrm{f}=4, p<0.001$ (HS) Hosmer and Lemeshow goodness of fit test $p=1.000$ (NS), $\beta$ regression coefficient, $S E$ standard error, $O R$ odds ratio, $95 \% \mathrm{Cl} 95 \%$ confidence interval. $p$ $<0.05$ is significant colleagues [21] in their prospective study conducted at Poursina Teaching-Hospital in Rasht, Iran, from January 2010 to the end of January 2011, where they found that in 98 cases with primary $\mathrm{ICH}$, the deceased patients have significantly higher NIHSS score $(p<0.001)$.

Different scoring systems have been tested and devised in order to improve the prediction of the outcome of primary $\mathrm{ICH}$, but they are not used routinely in clinical practice [22]. In our present study, a significant correlation was found between each of the four scores that have been used in patients' evaluation. mRS was positively correlated with ICH score, GCS, and NIHSS, and there is an inverse correlation found between ICH score and GCS.

In view of our results, we can conclude that in patients with primary $\mathrm{ICH}$ initial assessment on admission, using both the NIHSS and ICH scores (hematoma volume and GCS are included in ICH score) is much informative and predictive for the outcome than using any one of them alone and that NIHSS score has an independent predictive value of a 30-day outcome regarding mortality and disability.

\section{Abbreviations}

CRP: C-reactive protein; CT: Computerized tomography; ESR: Erythrocyte sedimentation rate; FAST: Factor seven for acute hemorrhagic stroke; FDA: Food and Drug Administration; GCS: Glasgow Coma Scale; H volume: Hematoma volume; HB: Level hemoglobin level; ICH: Intracerebral hemorrhage; IVH: Intraventricular hemorrhage; mRS: Modified Rankin score; NIHSS: National Institutes of Health Stroke Scale; SBP: Systolic blood pressure; WBCs: White blood cells; ZUH: Zagazig University Hospitals

Acknowledgements

Professor doctor, Adham Mahmoud Ismael, professor of neurology, ZUH, for his valuable revision and experts.

Funding

No funding resources more than authors contributions.

Availability of data and materials

The datasets used and /or analyzed during current study are available from the corresponding author on reasonable request. 


\section{Authors' contributions}

MM proposed the subject of research, wrote the review, and interpreted the collected data. NG analyzed the data, reviewed the results, and examined the patients. TE wrote the discussion and reviewed the references. WM edited the review and reviewed the discussion. All authors read and approved the final manuscript.

\section{Ethics approval and consent to participate}

The neurology department local ethical committee in Zagazig University, 8/ 2017.

An informed written consent was taken from patients or their relatives when their conscious level is below the level that permits him to give a consent.

\section{Consent for publication}

Not applicable.

\section{Competing interests}

The authors declare that they have no competing interests.

\section{Publisher's Note}

Springer Nature remains neutral with regard to jurisdictional claims in published maps and institutional affiliations.

Received: 28 July 2018 Accepted: 6 January 2019

Published online: 26 February 2019

\section{References}

1. Azab A, Saad M, Esmael A, El-Shehaby F. Prognostic significance of intraventricular extension in cases of spontaneous intracerebral hemorrhage. Egypt J Neurol Psychiat Neurosurg. 2006;43:243-52.

2. Feigin $\mathrm{VL}$, Forouzanfar $\mathrm{MH}$, Krishnamurthi $\mathrm{R}$, Mensah GA, Connor M, et al. Global and regional burden of stroke during 1990-2010: findings from the Global Burden of Disease Study 2010. Lancet. 2014;383:245-54.

3. Flower $\mathrm{O}$, Smith $\mathrm{M}$. The acute management of intracerebral hemorrhage. Curr Opin Crit Care. 2011;17:106-14

4. Samarasekera N, Fonville A, Lerpiniere C, Farrall AJ, Wardlaw JM, White PM, et al. Influence of intracerebral hemorrhage location on incidence, characteristics, and outcome population-based study. Stroke J. 2015:46:361-8.

5. Broderick J, Connolly S, Feldmann E, Hanley D, Kase C, Krieger D, et al. Guidelines for the management of spontaneous intracerebral hemorrhage in adults: 2007 update. Stroke J. 2007;38:2001-23.

6. Faigle R, Marsh EB, Llinas RH, Urrutia VC, Gottesman RF. Novel score predicting gastrostomy tube placement in intracerebral hemorrhage. Stroke. 2015;46:31-6.

7. Cheung RT, Zou LY. Use of the original, modified, or new Intracerebral Hemorrhage Score to predict mortality and morbidity after intracerebral hemorrhage. Stroke J. 2003:34:1717-22.

8. Goldstein LB, Samsa GP. Reliability of the National Institutes of Health Stroke Scale. Stroke J. 1997:28:307-10.

9. Adams H, Davis P, Leira EC, Chang KC, Bendixen BH, Clarke WR, et al. Baseline NIH Stroke Scale score strongly predicts outcome after stroke a report of the Trial of ORG 10172 in Acute Stroke Treatment (TOAST). Neurology. 1999:53:126-31.

10. Kothari RU, Brott E, Broderick JP, Barsan WJ, Sauerbeck LR, Zuccarello M, Khoury J. The ABCs of measuring intracerebral hemorrhage volumes. Stroke. 1996;27:1304-5.

11. Brouwers HB, Chang Y, Falcone GJ, Cai X, Ayres AM, Battey TW, et al. Predicting hematoma expansion after primary intracerebral hemorrhage. JAMA Neurol. 2014;71:158-64

12. Mustanoja S, Satopää J, Meretoja A, Putaala J, Strbian D, Curtze S, et al Extent of secondary intraventricular hemorrhage is an independent predictor of outcomes in intracerebral hemorrhage: data from the Helsinki ICH study. Int J Stroke. 2015;10:576-81.

13. Zis $P$, Leivadeas $P$, Michas $D$, Kravaritis D, Angelidakis $P$, Tavernarakis $A$ Predicting 30-day case fatality of primary inoperable intracerebral hemorrhage based on findings at the emergency department. J Stroke Cerebrovasc Dis. 2014;23:1928-33.

14. El-Tallawy HN, Shawky OA, Farghaly SM, Abdel Aziz A, Ashry M, Esmaeel M, et al. Parameters and $\mathrm{CT}$ brain findings of acute spontaneous intracerebral hemorrhage. Egypt J Neurol Psychiat Neurosurg. 2005;42:177-85.
15. Stein M, Luecke M, Preuss M, Scharbrodt W, Joedicke A, Oertel MF. The prediction of 30-day mortality and functional outcome in spontaneous intracerebral hemorrhage with secondary ventricular hemorrhage: a score comparison. Trends Neurovasc Surg. 2011;112:9-11.

16. Hu YZ, Wang JW, Luo BY. Epidemiological and clinical characteristics of 266 cases of intracerebral hemorrhage in Hangzhou, China. J Zhejiang Univ Sci B. 2013;14:496-504.

17. Christensen MC, Morris S, Vallejo-Torres L, Vincent C, Mayer SA, et al. Neurological impairment among survivors of intracerebral hemorrhage: the FAST trial. Neurocrit Care. 2012;16:224-31.

18. Hosomi N, Naya T, Ohkita H, Mukai M, Nakamura T, Ueno M, et al. Predictors of intracerebral hemorrhage severity and its outcome in Japanese stroke patients. Cerebrovasc Dis. 2009;27:67-74.

19. Finocchi C, Balestrino M, Malfatto L, Mancardi G, Serrati C, Gandolfo C. National Institutes of Health Stroke Scale in patients with primary intracerebral hemorrhage. Neurol Sci. 2018;39:1751-5.

20. Essa AY, Helmy TA, El Batch SA. Study of incidence, risk factors and outcome of acute cerebrovascular stroke patients admitted to Alexandria Main University Hospital. J Am Sci. 2011;7:316-29.

21. Bakhshayesh B, Hosseininezhad M, Saadat SM, Hajmanuchehri M, Kazemnezhad E, Ghayeghran AR. Predicting in-hospital mortality in Iranian patients with spontaneous intracerebral hemorrhage. Iran J Neurol. 2014;13:231-6.

22. Parry-Jones AR, Abid KA, Di Napoli M, Smith CJ, Vail A, Patel HC, et al. Accuracy and clinical usefulness of intracerebral hemorrhage grading scores a direct comparison in a UK population. Stroke. 2013:44:1840-5.

\section{Submit your manuscript to a SpringerOpen ${ }^{\circ}$ journal and benefit from:}

- Convenient online submission

- Rigorous peer review

- Open access: articles freely available online

High visibility within the field

- Retaining the copyright to your article

Submit your next manuscript at $>$ springeropen.com 